\title{
Reducing the Digital Divide among Children Who Received Desktop or Hybrid Computers for the Home
}

\author{
Gila Cohen Zilka \\ Bar-Ilan University, Achva Academic College, Israel \\ gila.zilka@gmail.com
}

\begin{abstract}
Researchers and policy makers have been exploring ways to reduce the digital divide. Parameters commonly used to examine the digital divide worldwide, as well as in this study, are: (a) the digital divide in the accessibility and mobility of the ICT infrastructure and of the content infrastructure (e.g., sites used in school); and (b) the digital divide in literacy skills. In the present study we examined the degree of effectiveness of receiving a desktop or hybrid computer for the home in reducing the digital divide among children of low socio-economic status aged 8-12 from various localities across Israel. The sample consisted of 1,248 respondents assessed in two measurements. As part of the mixed-method study, 128 children were also interviewed. Findings indicate that after the children received desktop or hybrid computers, changes occurred in their frequency of access, mobility, and computer literacy. Differences were found between the groups: hybrid computers reduce disparities and promote work with the computer and surfing the Internet more than do desktop computers. Narrowing the digital divide for this age group has many implications for the acquisition of skills and study habits, and consequently, for the realization of individual potential. The children spoke about self improvement as a result of exposure to the digital environment, about a sense of empowerment and of improvement in their advantage in the social fabric. Many children expressed a desire to continue their education and expand their knowledge of computer applications, the use of software, of games, and more. Therefore, if there is no computer in the home and it is necessary to decide between a desktop and a hybrid computer, a hybrid computer is preferable.
\end{abstract}

Keywords: Information and communication technology (ICT), digital divide, disadvantaged populations, desktop computers, hybrid computers, E-Readiness

\section{Introduction}

The Internet shatters the boundaries of time and place in the dissemination of information and

Material published as part of this publication, either on-line or in print, is copyrighted by the Informing Science Institute. Permission to make digital or paper copy of part or all of these works for personal or classroom use is granted without fee provided that the copies are not made or distributed for profit or commercial advantage AND that copies 1) bear this notice in full and 2) give the full citation on the first page. It is permissible to abstract these works so long as credit is given. To copy in all other cases or to republish or to post on a server or to redistribute to lists requires specific permission and payment of a fee. Contact Publisher@,InformingScience.org to request redistribution permission. allows a variety of communication options. But despite the potential the Internet offers to disadvantaged populations, the result in practice is the expansion of disparities between the affluent and the disadvantaged strata. Many research findings (Castells, 2009; Goyal, 2010; Hsieh, Rai, \& Keil, 2008; Sascha, James, \& James, 2011; Singh, 2008; Wang, Xu, \& Chan, 2008) show that 
there is a correlation between access to computers and the Internet, and socio-economic variables such as education, income, employment, financial feasibility, geographic location, and so on.

\section{Chance vs Risk}

On the one hand, the deployment of digital environments has the potential to reduce social inequalities and to provide equal opportunities for the entire population. On the other hand, there is a danger of exacerbating social inequalities because certain population groups lack access to digital environments, and of harming equal opportunity because these groups do not have access to digital environments. Researchers (Ching, Basham, \& Jang, 2005; Livingstone \& Sefton-Green, 2016; Losh, 2004; Wareham, Levy, \& Shi, 2004) warn that "digital apartheid" may ensue. Those who are not able to cope with the digital environment may become the new illiterates, with consequences for their employment, income, education, housing, and more. One of the main questions that arise is how to reduce the digital divide? The parameters used to examine the digital divide worldwide, as well as in the present study, are the following: (a) the digital divide in accessibility and mobility of the computer (i.e., a computer that can be transported from place to place, taken to school, to visit friends, etc., and that can be used for work or for surfing anyplace), of the ICT infrastructure and of content infrastructure (such as the sites used in school); and (b) the digital divide in literacy skills, such as word processing, graphics software, etc. In the present study we examined the degree of effectiveness of receiving a desktop or hybrid computer for the home in reducing the digital divide among Israeli children of low socio-economic status aged 812 because at this age literacy skills are being acquired in various fields, and because at this age children are forming learning and work habits. Specifically, this study asked the following questions:

What is the effectiveness of introducing a desktop or hybrid computer in the home in reducing the digital divide?

Will we find differences in effectiveness between children who received a desktop and those who received a hybrid computer?

Will we find differences in accessibility between the groups?

Does the mobility of the hybrid computer affect its effectiveness and the degree of accessibility?

Will we find differences between the two groups in browsing habits, use of the Internet, YouTube, etc., the use of computer applications such as word processing, graphics software, etc., and between the types of computers?

\section{Literature Review}

\section{Narrowing the Digital Divide}

The digital divide is defined as the gap between those who are digitally literate and have access to digital environments, and those who lack both. The difference is manifest in access, digital literacy, awareness, and the ability of individuals and organizations to use information technology as a means of production. In the same way as the printing press has dictated abilities and skills, so is learning in a digital environment associated with skills that characterize work in this environment. Developing these skills is a necessity. More and more occupations are carried out or supported in one way or another by digital environments. As a revolutionary, interactive mass medium, the Internet affects society and culture, politics and the economy, the right of the public to know and the right to privacy, and censorship. It has led to the collapse of hierarchical information, to equality of opportunity and social mobility, to interpersonal and mass communication, and so 
forth (Castells, 2009; Goyal, 2010; Hsieh et al., 2008; Sascha et al., 2011; Singh, 2008; Wang et al., 2008; Silka, 2012). But researchers (Castells, 2009; Goyal, 2010; Hsieh et al., 2008; Sascha et al., 2011; Singh, 2008; Wang et al., 2008) have shown that despite the potential of the Internet to advance disadvantaged populations, in practice it increases the divide between them and affluent populations. The studies listed above report on harm to equality of opportunity resulting from lack of access to the digital environment by these groups.

Disadvantaged populations are defined as having low socioeconomic status and multiple deprivations, with a correlation between variables such as income, housing, education, center or periphery (geographic center or periphery refers to the geographic distance from the centers of activity and education), access to digital environments, and more. There is a correlation between income and housing problems, low educational level, etc.

Researchers (Ching et al., 2005; Livingstone \& Sefton-Green, 2016; Losh, 2004; Wareham et al., 2004) have warned that those who are not able to negotiate digital environment may become the new illiterates, with consequences in a variety of fields such as employment, income, education, housing, and more.

\section{Computer for every child}

The Computer for Every Child project was established in 1996 with the aim to reduce the digital divide between affluent and disadvantaged populations. To accomplish this, it provides new computers, software kits, and training courses to children from disadvantaged communities who do not have computers at home. More than 62,000 computer kits were distributed and subsequently used by more than 280,000 children and parents. One of the main objectives of the distribution of computers to children who did not have one in the home was to give them the same opportunity that their peers have as far as their studies, homework, and school projects are concerned; to empower the children and their families; to grant equal opportunity to the children to realize their personal, economic, and social potential in the short and long terms, and thereby improve their ability to integrate into the global socio-economic and cultural fabric.

The Computer for Every Child project is still operating in Israel, and computers are still being handed out. The computers being handed out are new ones, with fast Internet connection. The study population included children who received computers in 2013-2014. During those years, the children received desktop PCs or hybrid computers. The study examined the effectiveness of introducing a computer into the home in narrowing the digital divide, and whether there was a difference between the groups of children who received a desktop PC and those who received a hybrid computer.

\section{Computer type}

In the course of 2014-2015, the children received new computers and a fast Internet connection.

The desktop and hybrid computers that were distributed contained identical software and learning environments. Hybrid computers consisted of a tablet computer with a keyboard and mouse in addition to the touch screen, a Windows operating system, Microsoft Office, fast Internet, and more.

\section{Measures of the Digital Divide}

Researchers (Agarwal, Animesh, \& Prasad, 2009; Dewan, Ganley \& Kraemer, 2004; HooperGreenhill, 2004; Hsieh et al., 2008; Zilka, 2012) have defined the measures of the digital divide. The digital divide concerns the availability and access to infrastructure and communication technology (ICT) infrastructure and to digital content, and the spread of literacy. Access to digital environments refers to access to computers, software, communication, and rapid access to infor- 
mation (Fox, 2004; Katz \& Rice, 2003; Shiblaq, 2008; Talukdar \& Gauri, 2011; Wareham et al., 2004; Zilka, 2006, 2012).

\section{Digital literacy and related skills}

Digital literacy (Zilka, 2006, 2010, 2011, 2012, 2014) refers to the set of skills required for negotiating digital learning environments and acquired through them. These environments include content in multiple representations (text, animations, sound, video, etc.); hypertext (content referencing additional content at different levels of depth); visual illustrations (images, simulations, films that illustrate natural phenomena, etc.); interactive elements that help the knowledge construction process in a friendly and play-oriented way; a variety of information sources, data processing programs, and more. The digital environments require familiarity with their characteristics, advantages, and limitations. Users must be able to work with a variety of tools and functions and must have the ability to combine various tools that expose them to the principles, strategies, and skills of literacy, and to the cultural and educational aspects needed for integrating the digital environment into the "work/study desktop."

\section{The Present Research}

In the preset study we focused on children aged 8-12 years because this is the age when literacy skills are acquired in various fields, and at this age, children are consolidating their learning and work habits. The aim of the study was to assess the effectiveness of receiving a desktop or hybrid computer for the home in reducing the digital divide for Israeli children of low socioeconomic status aged 8-12. We tested access to the Internet and the mobility of access, and the use of computer applications such as word processing, graphics software, etc.

\section{Research Method}

\section{The Study Population}

The sample consisted of 1,248 respondents (children who received computers during the years 2013-2014), assessed in two measurements. The first measurement took place before introducing the computer into the home; the second one approximately a year later. All the children were enrolled in regular primary schools. In the first measurement, 598 children were assessed, of whom $246(41 \%)$ received hybrid computers and 352 (59\%) desktop computers. In the second measurement, 650 children were examined, of whom 212 (32\%) received hybrid computers and 438 (68\%) desktop computers; 286 were boys and 298 girls. Some of the children had access to computers and the Internet in school. We found no differences in the number of hours spent on the computer in school between the first and second measurements; in other words, there was no difference in the number of computer hours in school. The effect of computer training in school on the children was manifest in both the first and the second measurements.

\section{Statistical processing}

To compare by consecutive measures the change that took place in the two groups following the intervention, we conducted a series of within-respondent factor analyses of variance. The withinrespondent factor was time (before, after) and the inter-respondent factor was group (children who received a hybrid and those who received a desktop computer).

Regarding questions relating to the children's reports on changes in their work, we examined the following statistical distributions of the variables: distributions, descriptive statistics, correlations between variables, regressions between the parameters themselves and between the parameters and socio-demographic variables, and chi-square tests. 


\section{Research Instruments}

Each participant was asked to answer a questionnaire containing a total of 92 closed-ended questions, once before the start of the intervention, and again after its completion. The items referred to the following themes: accessibility, mobility, and computer applications. In addition, as part of the second measurement, 128 personal interviews were conducted with the children: 50 children who received desktop computers and 78 children who received hybrid computers, with an equal distribution between boys and girls. We saw more children who received hybrid computers than children who received desktop computers because the hybrid computer is a relatively new medium, and because during the interviews we found differences in accessibility between the two groups of children, those who received a desktop and those who received a hybrid computer.

Below are the details of the research questions according to research topics:

1. Type of computer (desktop or hybrid): one question.

2. Accessibility and mobility. Total items and sub-items: 44 questions. Some questions were answered on a 5-point Likert scale ( 1 = not at all, 5 = very much, over 15 hours/week), for example: "Indicate the extent to which you use the computer at home, in school, at a public center." "Indicate the extent to which you surf the Internet." Other questions were answered on a 3-point scale ( 1 = often, 3 = never), for example: "Has it happened to you that your computer hung?" "Has it happened to you that the programs did not load?" "Has it happened to you that you don't understand the instructions or messages that the computer provides?" "Are you able to run any software that you are trying to run?" "How many smartphones are there in the family?" Based on this questionnaire, two main indicators of the digital divide in the access and mobility of ICT infrastructure were identified: mobility and accessibility (37 questions), and malfunctions and problems in computer use (7 questions).

3. Literacy skills. Total items and sub-items: 35 questions. Answers were provided on a 5point Likert scale $(1=$ not at all, $5=$ to the highest degree). Sample questions: "Indicate the extent of knowledge you have in word processing, graphics software, spreadsheets, multimedia software, and computer games." "Are you searching for content?" "Do you use databases?" Based on this questionnaire, two main indicators of the digital divide in literacy skills were identified: computer applications (24 questions) and searching content on the Internet (11 questions).

4. Personal information: 12 items, such as age, gender, sector, number of people in the home, and more.

\section{Research Process}

1. During 2013-2014 new computers with fast Internet connection were distributed to children who had no access to a computer at home.

2. The children underwent a 45-hour training course before receiving the computer.

3. At the final lesson of the course, the children completed the first measurement questionnaire and received the computer.

4. About ten months after receiving the computer, the children completed the second measurement questionnaire.

5. One hundred and twenty-eight in-depth interviews were conducted with the children, 50 of whom received desktop computers and 78 who received hybrid computers, with an equal distribution between boys and girls. 


\section{Results}

The research question was: What is the effectiveness of receiving a desktop or hybrid computer for the home in narrowing the digital divide among children of low socioeconomic status aged 812 ? Will the digital divide narrow after the children receive the computers?

The parameters used in Israel and elsewhere to assess the digital divide are: (a) the digital divide in the accessibility and mobility of ICT Infrastructure and of content infrastructure; and (b) the digital divide in literacy skills. To answer the research question, a series of analyses of variance was conducted with a between-subjects and a within-subject factor. The within-subject factor was time (before, after the intervention), and the between-subjects factor was group (children who received hybrid or desktop computers).

\section{Mobility and Accessibility}

The results show that the level of computer access and mobility of the children has risen sharply in the months during which the computer was available to them. Significant differences were found between the first and the second measurements. At the first measurement, the average for all respondents was 0.83 (on a scale of 0-4); at the second measurement, it was $1.52(\mathrm{~F}=106.16$, $\mathrm{P}<0.001$ ). At the second measurement, there was a difference between the children who received hybrid and desktop computers. At the first measurement, the average of the children who received hybrid computers was 0.96 , and at the second measurement it was 2.23 . At the first measurement, the average of the children who received desktop computers was 0.74 , and at the second measurement it was 1.27. At the second measurement, 387 children (out of 650) reported that they use computers between 1-5 hours per week (367 of these received desktop computers and 20 received hybrid computers); 189 children reported that the use computer between 6-10 hours per week (56 of these received desktop computers and 133 received hybrid computers). Frequency of use among the children who received hybrid computers was higher than that among children who received desktop computers, which was $1.02(\mathrm{~F}=28.24, \mathrm{P}<0.001)$.

At the second measurement, 387 out of 650 participating children responded that they used the computer 1-5 hours per week; 367 of these children received desktop computers and 20 children received hybrid computers. Another 189 children responded that they used the computer 6-10 hours per week; 56 of these children received a desktop and 133 received a hybrid computer. Figure 1 shows a sharper increase in indicators of accessibility and mobility among children who received a hybrid computer.

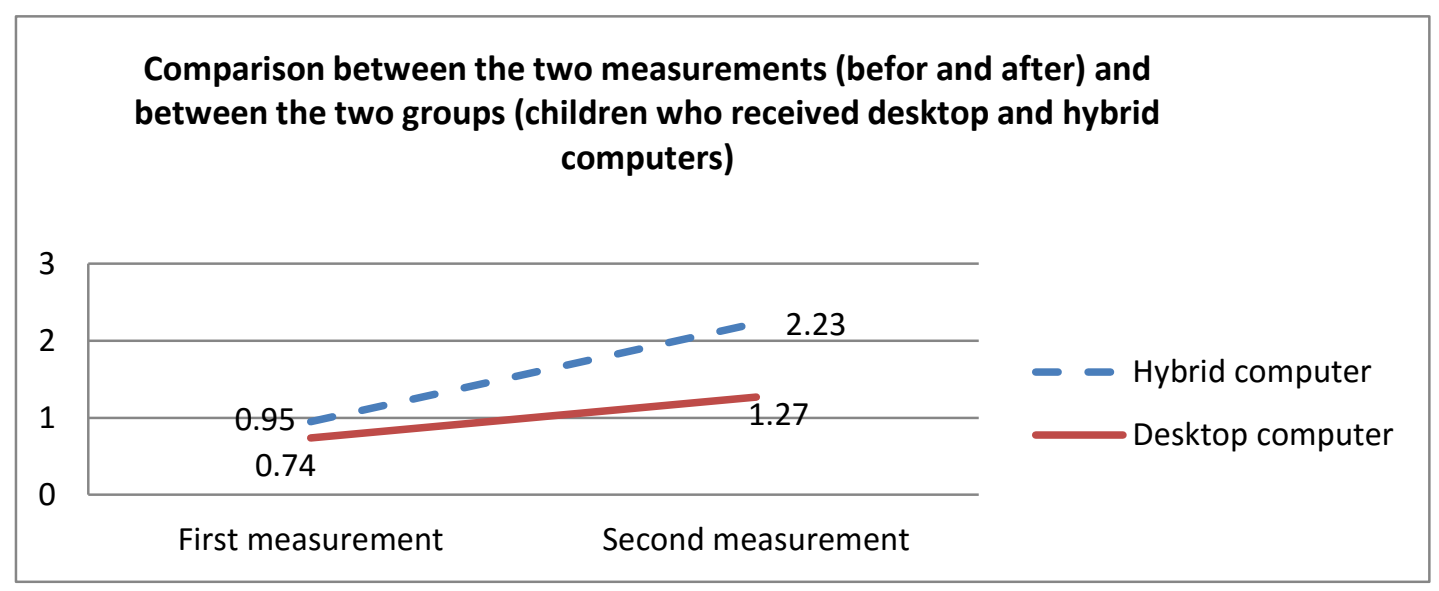

Figure 1. Interaction effect: Comparison between the two measurements (before and after) and between the two groups (children who received a hybrid and desktop computers) 
Figure 1 shows that the frequency of computer use at home increased between the first and the second measurements, with students who received a hybrid computer showing both a higher frequency and a higher growth rate.

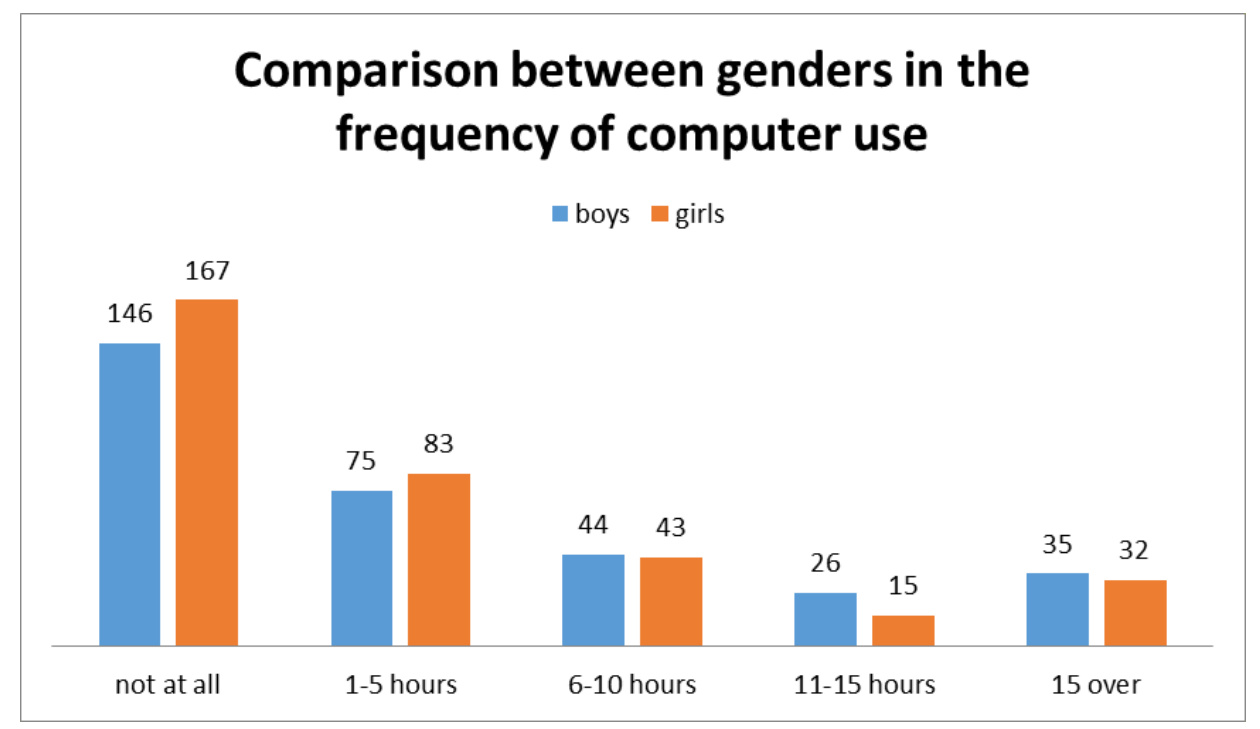

Figure 2. Comparison between genders in the frequency of computer use (ANOVA test).

Figure 2 shows that there is no significant difference between genders in the frequency of computer use.

\section{Surfing the Internet}

The results show that the frequency of surfing the Internet rose sharply in the months in which the computer was available to the children. Significant differences were found between the first and the second measurement in the frequency of Internet surfing. At the first measurement, the average of all participants was 1.26, whereas at the second measurement it was $1.54(\mathrm{~F}=12.30, \mathrm{P}<$ 0.001). A difference was found between the averages of the children who received hybrid (2.09) and of those who received desktop computers $(1.36)(\mathrm{F}=88.52, \mathrm{P}<0.001)$. The children who received hybrid computers showed a higher frequency of use than did those who received desktop computers, and the rate of increase in their use between the two measurements was higher.

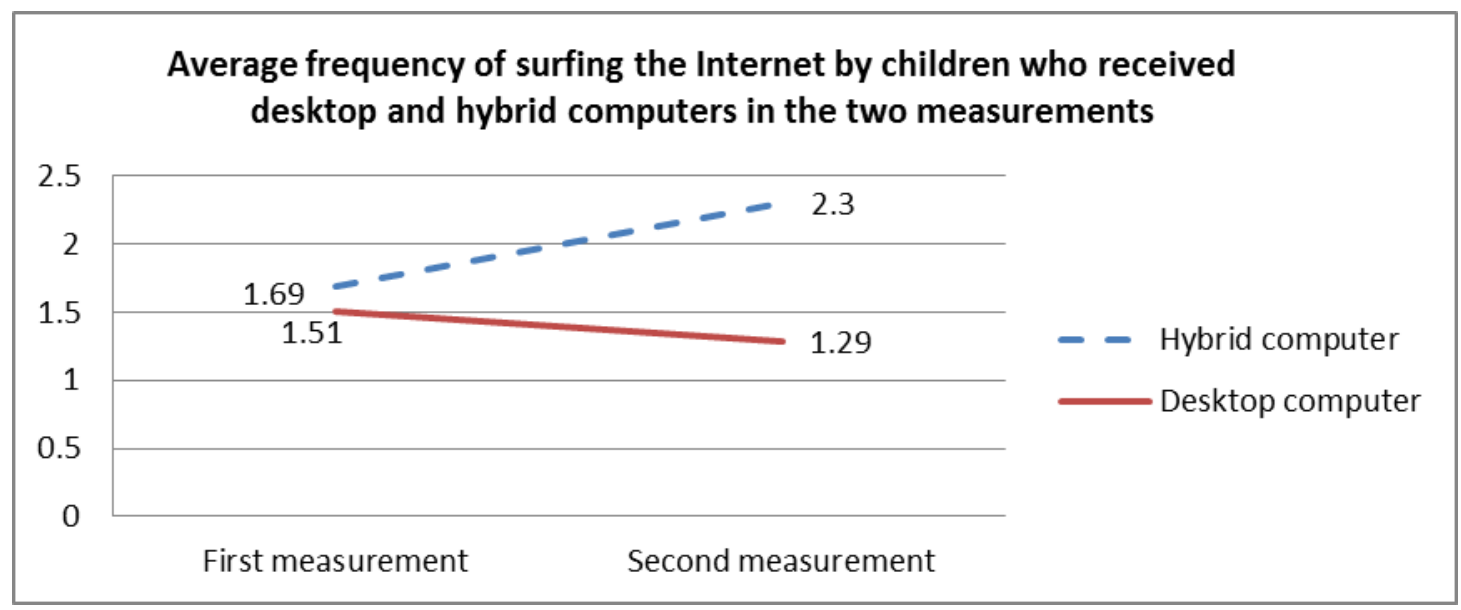

Figure 3. Interactive effect: Surfing the Internet 
Figure 3 shows that there was an increase between the first and second measurements in searching the Internet for materials needed to prepare homework and school assignments. The increase in the frequency of searches among students who received hybrid computers was higher than among those who received desktop computers.

\section{Watching Youtube}

The findings show that the frequency with which children watched Youtube increased greatly in the months in which the computer was available to them. Significant differences were found between the first and the second measurements in the frequency of Youtube use. At the first measurement, the average frequency of all participants was 1.1, whereas at the second measurement it was $1.32(\mathrm{~F}=10.59, \mathrm{P}<0.001)$. A difference was found between the averages of the children who received hybrid (1.53) and of those who received desktop computers (1.09) $(\mathrm{F}=50.01, \mathrm{P}<$ $0.001)$. The frequency of children who received hybrid computers, and their rate of increase, was higher at the second measurement. Figure 4 shows the average frequency of watching Youtube by children who received hybrid or desktop computers at both measurements.

Figure 4 shows that there was a difference between the two groups: the children who received hybrid computers showed higher frequency at both measurements, as well as a higher rate of increase (the children who received hybrid computers may have had more extensive prior knowledge).

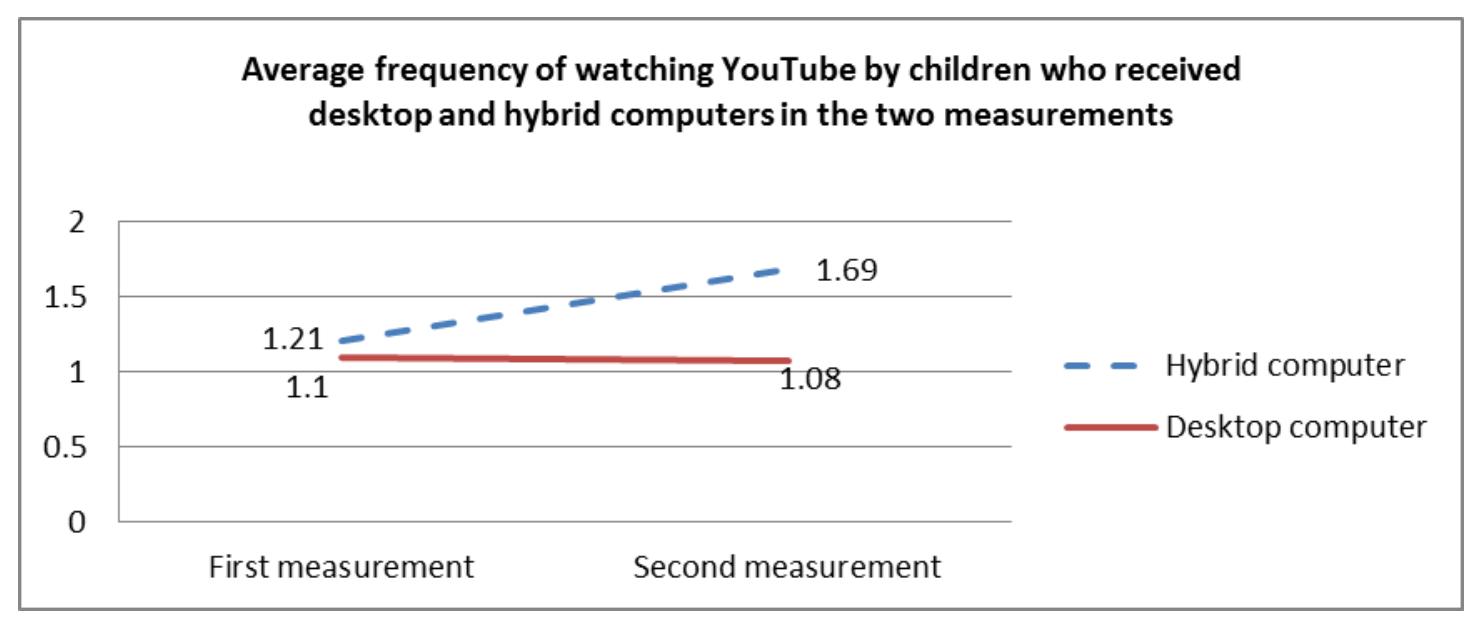

Figure 4. Watching Youtube

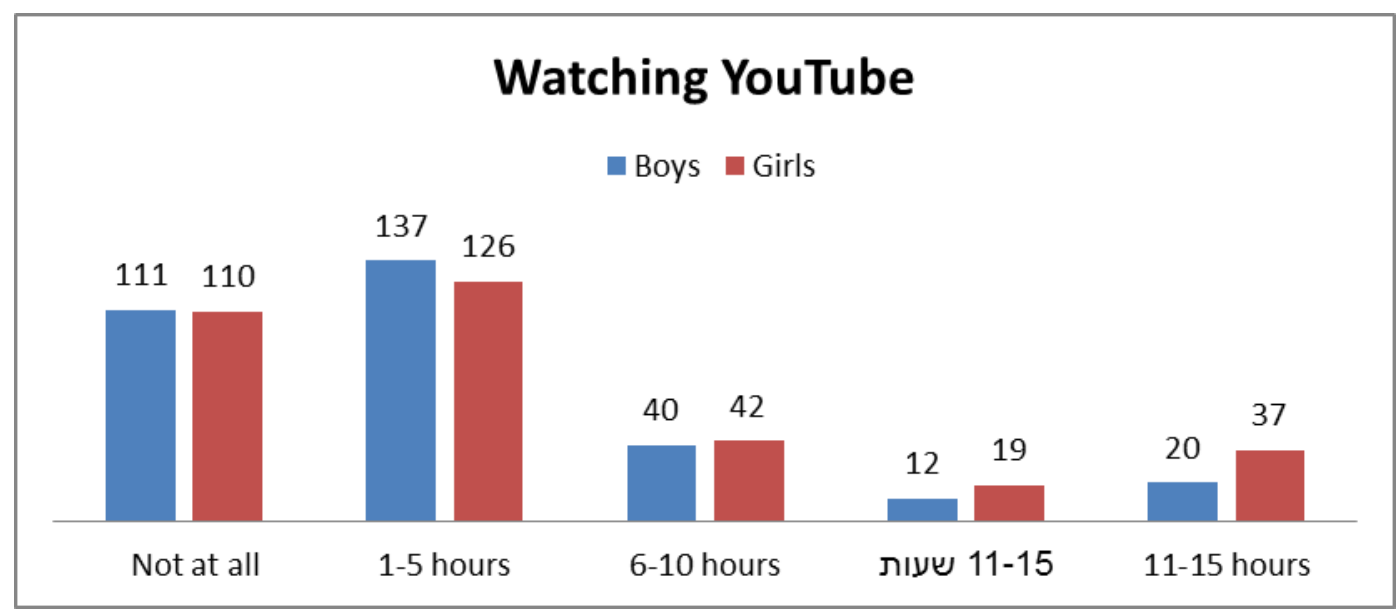

Figure 5. Gender differences in Youtube watching patterns 
As shown in Figure 5, the ANOVA test found significant differences between the genders in watching Youtube, with boys watching less on average (1.04) than girls (1.24).

Figure 6 shows that a difference was found between the groups of children, with those who received hybrid computers showing higher frequency at both measurements, as well as a higher rate of increase (the children who received hybrid computers may have had more extensive prior knowledge).

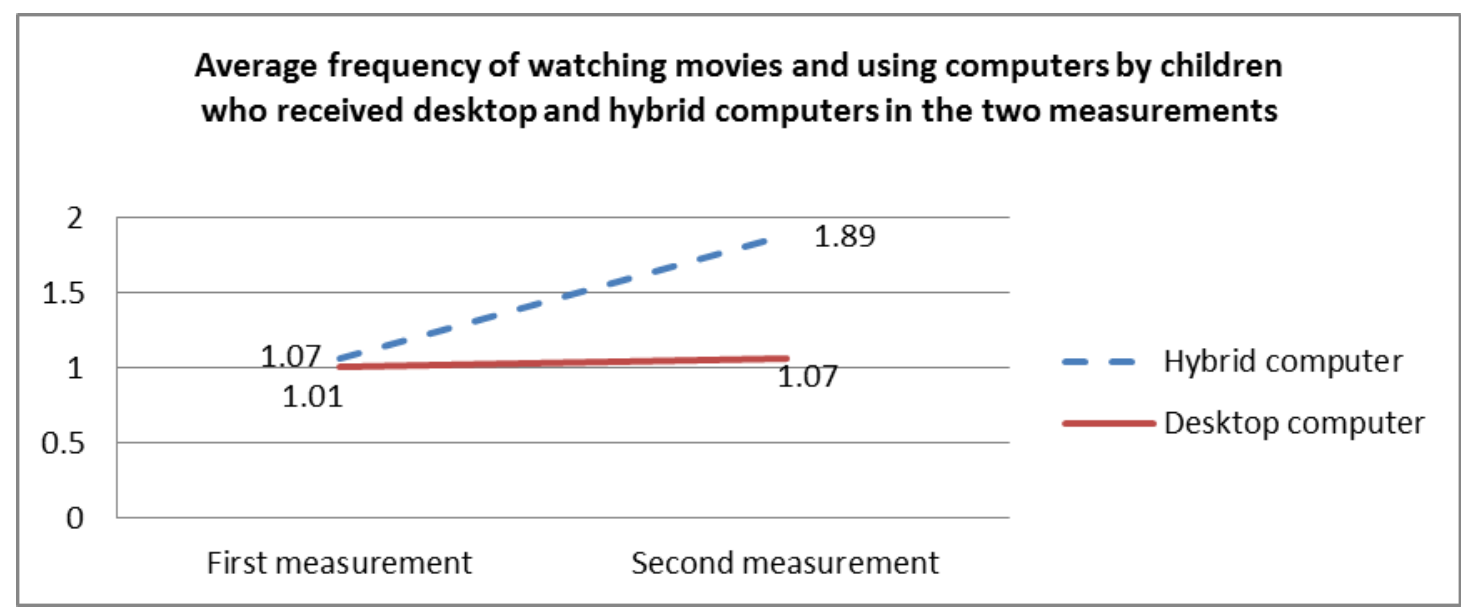

Figure 6. Interaction effect: Watching movies and using computer programs

The following data helped in interpreting the findings. The children were asked how many smartphones were owned by their families: $94.5 \%$ (605 children out of 650) answered that there were three or more smartphones in the family.

\section{Malfunctions and problems in computer use}

At the second measurement, we examined the extent of malfunctions and problems encountered by the children (Table 1). We found that in answer to the question "Has it happened to you that your computer hung?" the overall average was 1.74 . The average among children who received desktop computers was 1.89 , and the average among children who received hybrid computers was 1.44, so that children who received hybrid computers encountered fewer cases in which their computer hung than did children who received desktop computers. In answer to the question "Has it happened to you that the programs did not load?" the overall average was 1.72 . The average among children who received desktop computers was 1.89 , and the average among children who received hybrid computers was 1.35 , so that the children who received hybrid computers encountered fewer cases in which the software did not load than did the children who received desktop computers. In answer to the question "Has it happened to you that you did not understand the instructions given by the computer?" the overall average was 1.67 . The average among children who received desktop computers was 1.85 , and the average among children who received hybrid computers was 1.30 , so that the children who received hybrid computers encountered fewer unclear messages than did children who received desktop computers. In answer to the question "Has it happened to you that you were unable to work on the computer for a long time because there was no one to solve the problem?" the overall average was 1.71 . The average among children who received desktop computers was 1.86 , and the average among children who received hybrid computers was 1.40 , so that the children who received hybrid computers encountered fewer cases in which they were unable to work because of a malfunction of the computer than did children who received desktop computers. Seven percent of the children who received hybrid computers reported that their screen cracked or was broken. 
Table 1. Malfunctions and problems in computer use among children who received hybrid or desktop computers, reported at the second measurement on a scale of 0 to 3

\begin{tabular}{|c|c|c|c|c|c|c|c|c|}
\hline \multicolumn{3}{|c|}{$\begin{array}{l}\text { Malfunctions and problems in com- } \\
\text { puter use }\end{array}$} & \multirow{2}{*}{$\frac{\text { Mean }}{1.44}$} & \multirow{2}{*}{$\begin{array}{r}\begin{array}{l}\text { Std. Devia- } \\
\text { tion }\end{array} \\
.699\end{array}$} & $\mathrm{~N}$ & $F$ & Sig. & $\begin{array}{c}\text { Partial } \\
\text { Eta } \\
\text { Squared }\end{array}$ \\
\hline Has it hap- & Hybrid & 2.00 & & & 208 & & & \\
\hline pened to & & Total & 1.44 & .699 & 208 & & & \\
\hline you that the & Desktop & 2.00 & 1.89 & .410 & 438 & & & \\
\hline computer & & Total & 1.89 & .410 & 438 & & & \\
\hline hung? & Total & 2.00 & 1.74 & .561 & 646 & & & \\
\hline & & Total & 1.74 & .561 & 646 & 105.565 & .000 & .141 \\
\hline Has it hap- & Hybrid & 2.00 & 1.35 & .626 & 208 & & & \\
\hline pened to & & Total & 1.35 & .626 & 208 & & & \\
\hline you that the & Desktop & 2.00 & 1.89 & .420 & 438 & & & \\
\hline software & & Total & 1.89 & .420 & 438 & & & \\
\hline did not & Total & 2.00 & 1.72 & .558 & 646 & & & \\
\hline load? & & Total & 1.72 & .558 & 646 & 172.872 & .000 & .212 \\
\hline Has it hap- & Hybrid & 2.00 & 1.30 & .571 & 208 & & & \\
\hline pened that & & Total & 1.30 & .571 & 208 & & & \\
\hline you did not & Desktop & 2.00 & 1.85 & .379 & 438 & & & \\
\hline understand & & Total & 1.85 & .379 & 438 & & & \\
\hline the instruc- & Total & 2.00 & 1.67 & .518 & 646 & & & \\
\hline tions? & & Total & 1.67 & .518 & 646 & 210.096 & .000 & .246 \\
\hline Has it hap- & Hybrid & 2.00 & 1.40 & .681 & 208 & & & \\
\hline pened that & & Total & 1.40 & .681 & 208 & & & \\
\hline you could & Desktop & 2.00 & 1.86 & .396 & 438 & & & \\
\hline not work on & & Total & 1.86 & .396 & 438 & & & \\
\hline the com- & Total & 2.00 & 1.71 & .549 & 646 & & & \\
\hline $\begin{array}{l}\text { puter be- } \\
\text { cause there }\end{array}$ & & Total & 1.71 & .549 & 646 & 117.770 & .000 & .155 \\
\hline was no one & & & & & & & & \\
\hline to solve the & & & & & & & & \\
\hline problem? & & & & & & & & \\
\hline
\end{tabular}

\section{Mobility}

In questionnaires and interviews the children who received hybrid computers addressed the issue of the mobility of the computer. One of the narratives that emerged repeatedly in interviews with children who received hybrid computers was the mobility of the computer. 
Table. 2 Mobility: Excerpts illustrating six issues identified in the narratives of children who received hybrid computers for their homes

\begin{tabular}{|c|c|}
\hline Topics: Mobility & Quotations \\
\hline At home & $\begin{array}{l}\quad \text { I find a quiet corner in the house or on the porch and no one disturbs } \\
\text { me there. } \\
\checkmark \quad \text { I play computer games with my little brother on the staircase not to } \\
\text { disturb my older brothers and my parents. }\end{array}$ \\
\hline In school & $\begin{array}{l}\text { Today I'm a champ in computers. I bring the computer to school and } \\
\text { I explain to the other children what needs to be done and how all } \\
\text { kinds of things are done on the computer. }\end{array}$ \\
\hline Outside the home & $\begin{array}{l}\checkmark \quad \text { I was in the hospital for a few days and I took the computer with me. I } \\
\text { have so many things to do with the computer, I'm never bored when } \\
\text { it is with me. } \\
\checkmark \quad \text { I take the computer with me and I can do homework on the computer } \\
\text { anywhere. It is a lot more efficient for me. } \\
\checkmark \quad \text { It's more convenient, because when I'm traveling I'm not worried } \\
\text { when I'll be doing homework because I take the computer with me. }\end{array}$ \\
\hline Internet access & $\begin{array}{l}\checkmark \text { When I don't succeed to connect to the Internet someplace, I go with } \\
\text { the computer to some place where there is good and fast reception. } \\
\checkmark \quad \text { We had a problem connecting to the Internet, so I went with the } \\
\text { computer to my aunt's house and worked with the computer there. }\end{array}$ \\
\hline Extended family & $\begin{array}{l}\checkmark \quad \text { I go with the computer to my grandmother's to see the pictures on } \\
\text { the Facebook, pictures posted by my cousins and other uncles and } \\
\text { aunts, and she's happy to see their pictures and to read what they're } \\
\text { writing. }\end{array}$ \\
\hline Leisure & $\begin{array}{l}\checkmark \quad \text { I take the computer with me on long trips and so I no longer fight with } \\
\text { my brothers, I play with them on the computer or each one alone, } \\
\text { taking turns. } \\
\checkmark \quad \text { I'm never bored anymore when the computer is with me. }\end{array}$ \\
\hline
\end{tabular}

\section{Computer Literacy}

We found significant differences between the first and the second measurements in the degree of knowledge of computer applications (on the scale from 1 to 5). For word processors, the average of respondents at the first measurement was 2.17 and at the second measurement 3.18, showing a significant difference between the two measurements. Significant differences were found between the groups of children, with the children who received desktop computers making more extensive use of word processors than did the children who received hybrid computers (average of 3.39 at second measurement). For graphics software, the average of respondents at the first measurement was 1.99 and at the second measurement 2.86, showing a significant difference between the two measurements. We found no significant differences between the two groups. For multimedia software, the average of respondents at the first measurement was 1.39 and at the second measurement 2.70, showing a significant difference between the two measurements. We found no significant differences between the two groups. For computer games, the average of all respondents at the first measurement was 2.66 and at the second measurement 3.61, showing a significant difference between the two measurements. Many children expressed a desire to continue their studies and expand their knowledge of computer applications, the use of software, games, and more. 
Table 3. Interaction effect: Degree of knowledge of computer applications among children who received hybrid or desktop computers, showing the change between the two

measurements

\begin{tabular}{|c|c|c|c|c|c|c|c|c|}
\hline \multicolumn{3}{|c|}{$\begin{array}{l}\text { Indicate the extent of knowledge } \\
\text { you have in the following } \\
\text { computer applications: }\end{array}$} & \multirow{2}{*}{$\frac{\text { Mean }}{2.47}$} & \multirow{2}{*}{$\begin{array}{l}\begin{array}{l}\text { Std. De- } \\
\text { viation }\end{array} \\
1.391\end{array}$} & \multirow{2}{*}{$\frac{\mathrm{N}}{121}$} & \multirow[t]{2}{*}{$\mathrm{F}$} & \multirow[t]{2}{*}{ Sig. } & $\begin{array}{l}\text { Partial } \\
\text { Eta } \\
\text { Squared }\end{array}$ \\
\hline \multirow{9}{*}{$\begin{array}{l}\text { Word } \\
\text { processor }\end{array}$} & \multirow{3}{*}{$\begin{array}{l}\text { Hybrid } \\
\text { Total }\end{array}$} & 1.00 & & & & & & \\
\hline & & \multirow[t]{2}{*}{2.00} & 3.08 & .908 & 202 & & & \\
\hline & & & 2.85 & 1.150 & 323 & & & \\
\hline & \multirow[t]{3}{*}{ Desktop } & 1.00 & 2.00 & 1.427 & 200 & & & \\
\hline & & 2.00 & 3.39 & 1.085 & 95 & & & \\
\hline & & Total & 2.44 & 1.476 & 295 & & & \\
\hline & \multirow[t]{3}{*}{ Total } & 1.00 & 2.17 & 1.430 & 321 & & & \\
\hline & & 2.00 & 3.18 & .976 & 297 & & & \\
\hline & & Total & 2.66 & 1.331 & 618 & 14.28 & .00 & .023 \\
\hline \multirow{9}{*}{$\begin{array}{l}\text { Graphics } \\
\text { software } \\
\text { (PowerPoint, } \\
\text { PhotoShop, } \\
\text { etc.) }\end{array}$} & \multirow[t]{3}{*}{ Hybrid } & 1.00 & 2.31 & 1.471 & 121 & & & \\
\hline & & 2.00 & 2.68 & 1.093 & 202 & & & \\
\hline & & Total & 2.54 & 1.259 & 323 & & & \\
\hline & \multirow[t]{3}{*}{ Desktop } & 1.00 & 1.80 & 1.494 & 200 & & & \\
\hline & & 2.00 & 3.23 & 1.224 & 95 & & & \\
\hline & & Total & 2.26 & 1.562 & 295 & & & \\
\hline & \multirow[t]{3}{*}{ Total } & 1.00 & 1.99 & 1.503 & 321 & & & \\
\hline & & 2.00 & 2.86 & 1.164 & 297 & & & \\
\hline & & Total & 2.41 & 1.417 & 618 & 22.09 & .00 & .035 \\
\hline \multirow{9}{*}{$\begin{array}{l}\text { Multimedia } \\
\text { software } \\
\text { (video, } \\
\text { music } \\
\text { editing) }\end{array}$} & \multirow[t]{3}{*}{ Hybrid } & 1.00 & 1.55 & 1.461 & 121 & & & \\
\hline & & 2.00 & 2.57 & 1.277 & 202 & & & \\
\hline & & Total & 2.19 & 1.435 & 323 & & & \\
\hline & \multirow[t]{3}{*}{ Desktop } & 1.00 & 1.30 & 1.403 & 200 & & & \\
\hline & & 2.00 & 2.99 & 1.519 & 95 & & & \\
\hline & & Total & 1.84 & 1.643 & 295 & & & \\
\hline & \multirow[t]{3}{*}{ Total } & 1.00 & 1.39 & 1.428 & 321 & & & \\
\hline & & 2.00 & 2.70 & 1.370 & 297 & & & \\
\hline & & Total & 2.02 & 1.546 & 618 & 8.059 & .00 & .013 \\
\hline \multirow{9}{*}{$\begin{array}{l}\text { Computer } \\
\text { games }\end{array}$} & \multirow[t]{3}{*}{ Hybrid } & 1.00 & 2.83 & 1.370 & 121 & & & \\
\hline & & 2.00 & 3.70 & .734 & 202 & & & \\
\hline & & Total & 3.37 & 1.103 & 323 & & & \\
\hline & \multirow[t]{3}{*}{ Desktop } & 1.00 & 2.56 & 1.568 & 200 & & & \\
\hline & & 2.00 & 3.40 & 1.115 & 95 & & & \\
\hline & & Total & 2.83 & 1.489 & 295 & & & \\
\hline & \multirow[t]{3}{*}{ Total } & 1.00 & 2.66 & 1.500 & 321 & & & \\
\hline & & 2.00 & 3.61 & .883 & 297 & & & \\
\hline & & Total & 3.11 & 1.329 & 618 & 0.23 & $\begin{array}{r}.88 \\
1 \\
\end{array}$ & .000 \\
\hline
\end{tabular}




\section{Searching for online content}

To test the differences between the measurements before and after the intervention regarding the question "Are you searching for content on the Internet?" we conducted a variance analysis, with frequency of Internet searching as the dependent variable, and with time of measurement and type of computer as independent variables. We found a significant main effect for time of measurement, as well as a significant interaction effect. The main effect for time of measurement indicated that at the second measurement $(\mathrm{m}=2.98)$, on average, the children searched for content more than at the first measurement $(\mathrm{m}=2.10)$. We also found a main effect for type of computer, showing that on average, children who received hybrid computers $(m=3.09)$ used the computer more to search for content on the Internet than did children who received desktop computers $(m=2.73)$. Figure 7 shows that there was an increase between the first and second measurements in searching the Internet for materials needed to prepare homework and school assignments. The increase in frequency of searches among students who used hybrid computers was higher than among those who received desktop computers.

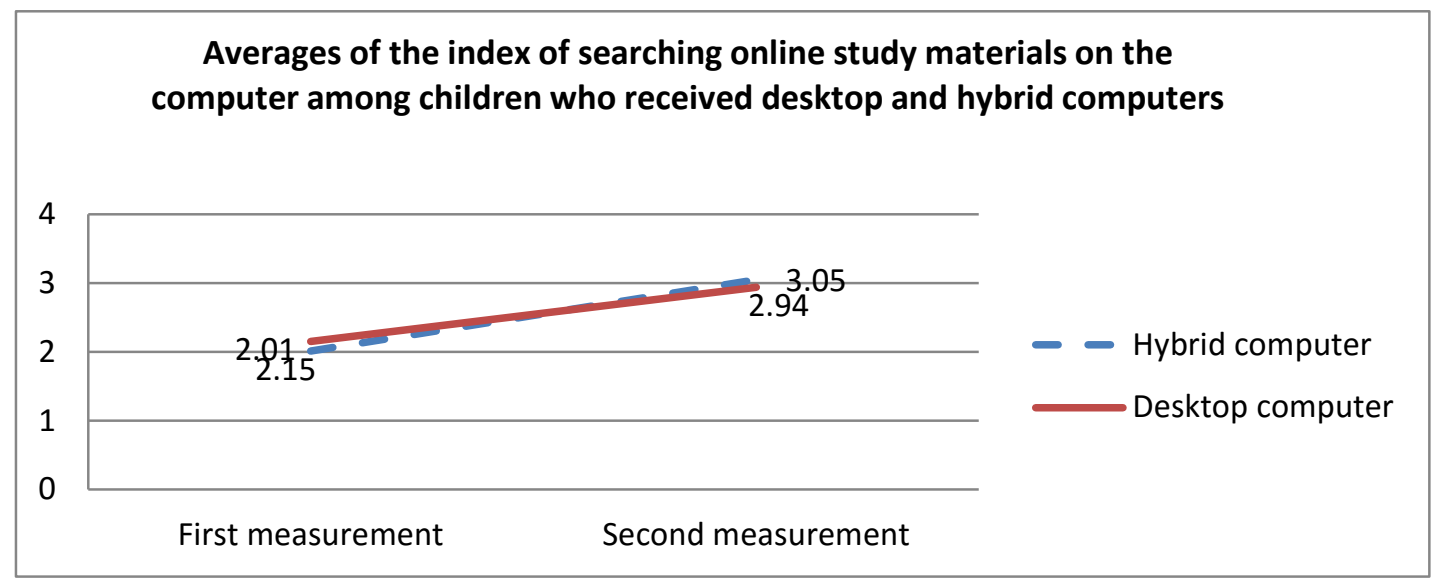

Figure 7. Interaction effect: Searching databases among children who received hybrid or desktop computers at both measurements

An ANOVA analysis shows that there are significant differences between boys and girls in the frequency of Internet searches for content. On average, girls made more use of the Internet to search for the study materials (2.24) than did boys (1.99).

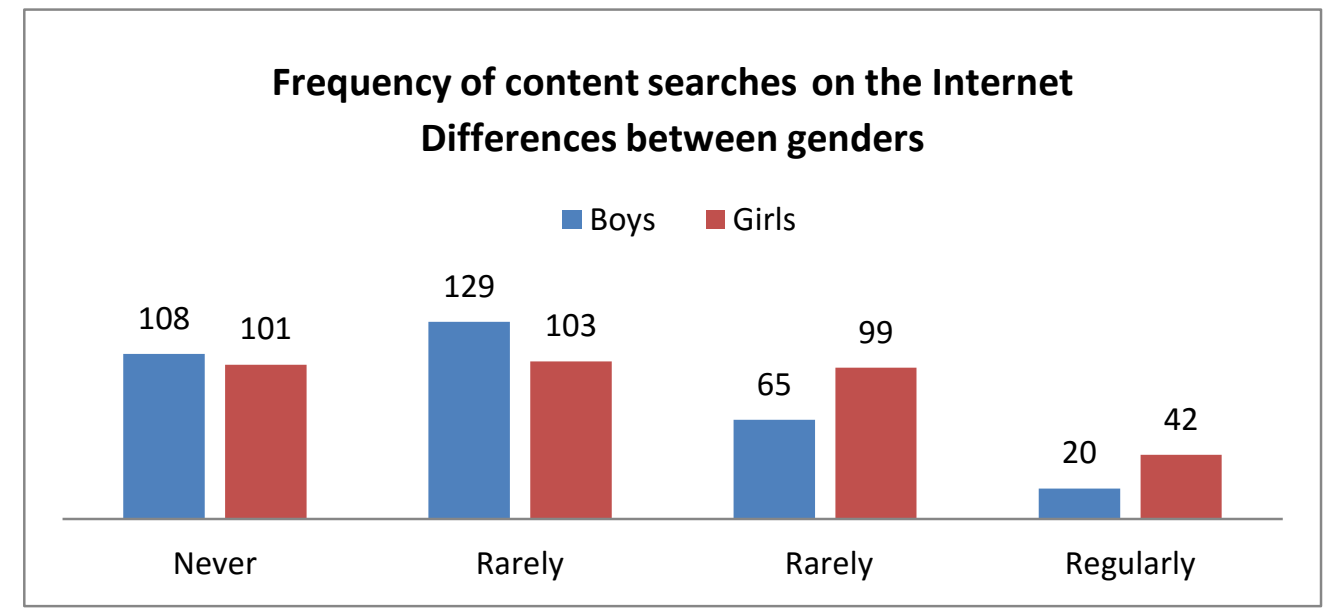

Figure 8. Comparison between genders in frequency of Internet searches for content 


\section{Conclusion}

The research question was: What is the effectiveness of receiving a desktop or hybrid computer for the home in narrowing the digital divide among low socioeconomic status children aged 8-12? To assess the digital divide, the study was based on the parameters that are commonly used in Israel and worldwide: the digital divide in the accessibility and mobility of the ICT infrastructure and of the content infrastructure (such as websites used in school), and the digital divide in literacy skills.

The results show that significant changes took place between the two measurements in computer usage and Internet browsing habits. We therefore conclude that to some extent the digital divide was narrowed among children who received a desktop or hybrid computer for home use. Although the children had access to computers at school, the findings show significant differences between the first and second measurements on almost all indicators, suggesting that a home computer brought significant changes in access and computer literacy. The children completed the questionnaires following a 45-hour training course. Additionally, some of the children attended computer classes at school. Nevertheless, after the children received a computer for home use there was a significant change in their access and computer literacy. Similar findings on reducing the digital divide were reported by previous studies (Aladjem \& Nachmias, 2011; Brandt, 2015; Bulger \& Livingstone, 2013; Cochrane, Narayan, \& Oldfield, 2013; Conners-Burrow, McKelvey, \& Fussell, 2011; Hampton, Sessions, \& Ja Her, 2011; Jacobs, 2013; Jacobson \& Macke, 2013; Wei, Teo, Tan, \& Chan, 2011; Zilka, 2011, 2012). It has been found that a desktop or hybrid computer in the home may narrow the divide and create equal opportunities. Differences were found between the groups, indicating that hybrid computers accelerate the narrowing of the divide and promote wider use of the computer for school work and for surfing the Internet than do desktop computers.

\section{Accessibility and Mobility}

The results showed that the level of access of children increased in the months in which the computer was available to them. Significant differences were found between the first and second measurements in the frequency of computer use. The results show a sharper increase in accessibility and mobility among children who received hybrid than among those who received desktop computers; children who received hybrid computers used the computer more, surfed the Internet and databases more, and searched more for content than did children who received desktop computers.

Children who received hybrid computers noted the enjoyment they derived from their use and mobility. Many children stated that they took their computer with them everywhere, that the computer helped them integrate into the fabric of the classroom, that they were never bored anymore, that they played computer games with their siblings, and more. The children noted the ease of use of the hybrid computer. We found that the majority of families (of all respondents) have three or more smartphones connected to the Internet, and many children said that they had used a smartphone before receiving a home computer. Using the smartphones enabled them to develop skills needed to work with a touch screen, and upon receiving the hybrid computer, they were immediately able to work with the computer they received. This finding supports those of Hampton, et al. (2011), who reported that access to smartphones narrows the digital divide.

Previous studies reported similar findings about Internet access narrowing the digital divide (Fox, 2004; Katz \& Rice, 2003; Shiblaq, 2008; Talukdar \& Gauri, 2011; Wareham et al., 2004; Zilka, 2012, 2006). The novelty in the present study is the comparison between hybrid and desktop computers, and in the presence of smartphones in the family. Although these families are in the category of disadvantaged populations, they have access to smartphones, and the presence of 
smartphones connected to the Internet narrows to a certain extent the digital divide, as found by Hampton, et al., 2011.

\section{Malfunctions and problems}

At the second measurement, we assessed the extent to which children encountered malfunctions and problems. We found that children who received hybrid computers encountered fewer instances in which the computer hung, encountered fewer unclear messages, and reported fewer cases in which they were unable to work on the computer because of a malfunction, than did children who received desktop computers. But $7 \%$ of the children who received hybrid computers noted that the screen cracked or broke, which suggests that hybrid computers have a lower survival rate than do desktop computers.

\section{Computer Literacy}

Significant differences were found between the first and the second measurements in the degree of knowledge in computer applications, such as word processing and graphics software. Most children logged in from home to the Internet learning environments used in the school. Most children processed information obtained from the Internet using data processing tools, typically word processors and graphics software. Many children expressed a desire to continue their studies and expand their knowledge of computer applications, software, games, and more. Similar findings concerning literacy and reducing the digital divide were reported in previous studies (Brandt, 2015; Bulger \& Livingstone, 2013; Hatlevik, Guðmundsdóttir, \& Loi, 2015; Hooper-Greenhill, 2004; Jacobs, 2013; Robinson, Dimaggio, \& Hargittai, 2003; Zilka, 2010, 2011, 2012). The novelty of the present study lies in the comparison between desktop and hybrid computers, with two characteristics of the latter having been found critical: mobility and touch screen. These two characteristics made the hybrid computers more available and easier to use.

The findings, questionnaires, and interviews reveal that the children's awareness of digital environments has greatly increased in the months in which the computer was available to them. At the first measurement, before receiving the computer, the children wrote that they did not need a computer to do their homework, they did not receive assignments that required a computer or Internet, and that they did not feel that a computer would assist or enrich them in matters related to school work. At the second measurement, they already discovered that the computer helped in writing, reading, collecting material, organizing material, and more. It turned out that the potential of the computer was revealed when it was being used. The digital environment allows flexibility in processing the data and in presenting it by means of various applications.

The results show that a change occurred between the two measurements in the use of the Internet, and that the children surfed online databases more at the second than at the first measurement. Differences were found between groups by type of computer, with children who received hybrid computers surfing databases more that did children who received desktop computers. A change occurred in the averages of downloads of movies, music, and games between the two measurements. Differences were found between the groups by type of computer, with children who received hybrid computers downloading more movies, music, and games than did those who received desktop computers. Significant differences were found between boys and girls in the frequency of searches for online materials. Girls used the Internet more to search for content than boys did.

The results show that a change occurred between the two measurements in the use of the Internet for individual advancement, including the understanding of the potential of the computer for personal advancement. Most children logged in from home to Internet learning environments used in the school. Most children processed information obtained from the Internet using data processing 
tools, typically word processors and graphics software. Some of the children were able to implement advanced exploration methods in their searching, integrating strategies for assessing the information sources. The strategies they integrated depended on prior learning and on internalizing strategies learned in school and during the training course they had received. Additionally, the children internalized certain strategies and forgot others that had been learned in school and in the training course, in accordance with their personal inclinations, for example: a tendency to work seriously, accurately, to reach deep levels, etc., as opposed to an individual tendency to finish tasks as quickly as possible, without applying strategies for intelligent content search, to focus on the first results displayed by the search engine, and so on.

In sum, significant changes occurred between the two measurements in accessibility and mobility and in literacy skills. We therefore conclude that, to some extent the digital divide was narrowed, and that a computer at home, whether desktop or hybrid, may narrow gaps and create equal opportunities. Differences were found between the groups. Hybrid computers accelerate the narrowing of the disparity, and promote wider use of computers for work and more extensive browsing of the Internet than do desktop computers. Narrowing the digital divide at ages 8-12 has many implications, including in matters related to learning skills and habits, for the realization of the personal, social, and economic potential of the children in the short and long terms, improving their ability to integrate into the global social, economic, and cultural fabric. Organizations worldwide, similar to Computer for Every Child in Israel, should help families of disadvantaged populations obtain a computer for the home or assist them in purchasing one. Furthermore, it is essential to raise the awareness of these populations to the importance of having a computer in the home, of acquiring the appropriate skills and study habits for realizing their personal potential, for achieving social mobility, and for reducing social disparities. It is important to explain that lack of access to a computer can exacerbate social inequality and harm equality of opportunity. Because there is a significant correlation between the digital divide and other social disparities (such as housing, education, income, employment, geographic location, etc.), reducing the digital divide can help reduce social inequality and enhance social mobility.

When there is no computer in the home, children cannot accumulate the computer time that would allow them to acquire work habits and develop awareness of the potential of the digital environment. The present study showed that only after receiving a computer in the home did computer literacy skills acquired at school and elsewhere become usable. The first questionnaire administered before the introduction of the computer in the home found that participants had a sense of helplessness and of lack of self-efficacy in handling a computer, and a lack of understanding and awareness of the possibilities available within the digital environment. For example, at the first measurement, before they received the computer, the children wrote that they did not need a computer to do homework, that they did not receive assignments requiring a computer or Internet, and that they did not feel that a computer would assist or enrich them in school-related matters. At the second measurement, conducted a year after receiving the computer, they already discovered that the computer helps in writing, reading, collecting and organizing material, etc. Thus, we found that the potential of the computer is revealed in the course of usage. The digital environment allows flexibility in the processing and display of data, using various applications. For example, writing and processing text with a word processor makes available a learning environment that frees learners from fears and inhibitions that characterize the pen and paper environment. Learners can change and add to their text, and exercise reflective discretion without fear because the text is never final. The computer frees the children from having to worry about margins, the correct writing of the letters, the proper spacing of the letters and of the words, and so on. This page always remains clean. The software also flags possible spelling errors in a clean and pleasant format and offers suggestions to correct them. We found that children encountered the need for information and had to search for it on the Internet and in databases; that they had to prepare homework and school work on the computer; that they had to use computer applications 
for text processing (such as word processing software, graphics software, etc.), and to integrate repetitive processes in their work with the computer.

A high level of awareness of individuals of the advantages and hazards of this environment leads to the understanding that a substantial change has occurred following the appearance of digital environments in various areas of life, and that the digital environment can be the key and the stepping stone to personal advancement and realization. Awareness is related to self-esteem, which in turn can lead to a breakthrough in life.

One of the objectives in reducing the digital divide was to allow users in this environment to realize their personal, social, and economic potential, and thereby improve their advantage in the global cultural-economic fabric. In the interviews, the children talked about things they were not aware of before they obtained a home computer, and noted that subsequently they came to understand the options available to them. The children spoke about self-leverage as a result of exposure to the digital environment, about a sense of empowerment and of improvement in their advantage in the social fabric. Many children expressed a desire to continue their education and expand their knowledge of computer applications, the use of software, of games, and more.

\section{References}

Agarwal, R., Animesh, A., \& Prasad, K. (2009). Research note - Social interactions and the "digital divide”: Explaining variations in internet use. Information Systems Research, 20(2), 277-294

Aladjem, R., \& Nachmias, R. (2011). Constructing knowledge via mobile devices - one interaction at a time. International Journal of Technology Enhanced Learning, 3(6), 599-607.

Brandt, D. (2015). The rise of writing: Redefining mass literacy. Cambridge, UK: Cambridge University Press.

Bulger, M., \& Livingstone, S. (2013). Media literacy research and policy in Europe: A review of recent current and planned activities. Report of a seminar organised by the COST Transforming Audiences, Transforming Societies Action, Brussels, September.

Castells, M. (2009). Communication power. New York: Oxford University Press.

Ching, C. C., Basham, J. D., \& Jang, E. (2005). The legacy of the digital divide, gender, socioeconomic status, and early exposure as predictors of full-spectrum technology use among young adults. Urban Ed., 40, 394-411.

Cochrane, T., Narayan, V., \& Oldfield, J. (2013). iPadagogy: Appropriating the iPad within pedagogical contexts. International Journal of Mobile Learning and Organisation, 7(1), 48-65.

Conners-Burrow, N. A., McKelvey, L. M., \& Fussell, J. J. (2011). Social outcomes associated with media viewing habits of low-income preschool children. Early Education and Development, 22(2), 256-273.

Dewan, S., Ganley, D., \& Kraemer, K. L. (2004). Across the digital divide: A cross-country analysis of the determinants of IT penetration. Working Paper, Personal Computing Industry Center, Graduate School of Management. University of California, Irvine, November.

Fox, S. (2004). Older Americans and the Internet. Pew Internet and American Life Project: 22. Washington D.C. Retrieved from http://www.pewinternet.org/pdfs/PIP_Seniors_Online_2004.pdf

Goyal, A. (2010). Information, direct access to farmers, and rural market performance in central India. American Economic Journal: Applied Economics, 2(3), 22-45.

Hampton, K. N., Sessions, L. F., \& Ja Her, E. (2011). Core networks, social isolation, and new media: How Internet and mobile phone use is related to network size and diversity. Information, Communication \& Society, 14(1), 130-155. 
Hatlevik, O. E., Guðmundsdóttir, G. B., \& Loi, M. (2015). Examining factors predicting students’ digital competence. Journal of Information Technology Education: Research, 14, 123-137. Retrieved from http://www.informingscience.org/Publications/2126

Hooper-Greenhill, E. (2004). Measuring learning outcomes in museums, archives, and libraries: The learning impact research project (LIRP). International Journal of Heritage Studies, 10, 151-174.

Hsieh, J. J., Rai, A., \& Keil, M. (2008). Understanding digital inequality: Comparing continued use behavioral models of the social-economically advantaged and disadvantaged. MIS Quarterly, 32, 97-126.

Jacobs, L. M. J. (2013). Minding the gaps: Exploring the space between vision and assessment in information literacy work. Communications in Information Literacy, 7(2).

Jacobson, T. E., \& Macke, T. P. (2013). Proposing a metaliteracy model to redefine information literacy. Communications in Information Literacy, 7(2), 84-91.

Katz, J. E., \& Rice, R. E. (2003). Comparing internet and mobile phone usage: Digital divides of usage, adoption, and dropouts. Telecommunications Policy, 27(8-9), 597-623.

Livingstone, S., \& Sefton-Green, J. (2016). The class: Living and learning in the digital age. New York: NYU Press.

Losh, S. C. (2004). Gender, educational, and occupational digital gaps. Social Science Computer Review, 22(2), 152.

Robinson, J. P., Dimaggio, P., \& Hargittai, E. (2003). New social survey perspectives on the digital divide. IT \& Society 1(5), 1-22.

Sascha, M. S., James, L., \& James, L. (2011). A growing digital divide: Internet freedom and the negative impact of command-and-control networking. New America Foundation, Internet Computing, IEEE, 15(4), 75-79.

Singh, N. (2008). Crossing a chasm: Technologies, institutions and policies for developing a regional IT industry. In A. Saith, M. Vijayabaskar, \& V. Gayathri (Eds.). ICTs and Indian social change: diffusion, poverty and governance (pp.192-218). New Delhi: Sage Publications.

Shiblaq, F. K. (2008). ICT in rural New Zealand: A review of the literature. Bulletin of Applied Computing and Information Technology, 6(1).

Talukdar, D., \& Gauri, D. K. (2011). Home internet access and usage in the USA: Trends in the socioeconomic digital divide. Communications of the Association for Information Systems, 28(Feb.), 85-98.

Wang, D., Xu, L., \& Chan, H. C. (2008). Understanding users' continuance of Facebook: The role of general and specific computer self-efficacy. Proceedings International Conference on Information Systems (ICIS 2008).

Wareham, J., Levy, A., \& Shi, W. (2004). Wireless diffusion and mobile computing: Implications for the digital divide. Telecommunications Policy, 28(5-6), 439-457.

Wei, K. K., Teo, H. H., Chan, H. C., \& Tan, C. C. (2011). Conceptualizing and testing a social cognitive model of the digital divide. Information Systems Research, 22(1), 170-187.

Zilka, G. (2006). Boys and girls in the instant messaging environment. In L. Birch \& E. Gilad (Eds.), My voice, your voice, gender, education, and society (pp.113-144). Achva College of Education: Institute for the Study of Gender. (Hebrew)

Zilka, G. (2010). Boys and girls in the digital learning environment. In A. Gilad, M. Shcter, S. Melat (Eds.), Gender dialogue in education, practice and theory (pp. 33-70). Achva Academic College. (Hebrew)

Zilka, G. (2011). Digital environment in the kindergartens. In D. Chen, \& G. Kurtz (Eds.), ICT, learning and teaching (pp. 207-230). The Center for Academic Studies. Or-Yehuda. (Hebrew)

Zilka, G. (2012). Reducing the digital gap among underserved populations in Israel. Ma'of u-Ma'aseh Teaching and Learning in the Internet Era 14. Achva Academic College. 101-138. (Hebrew) 
Zilka, G. (2014). Empowering educators and mentors in the social media age: The three element way. Butan-Galim. (Hebrew)

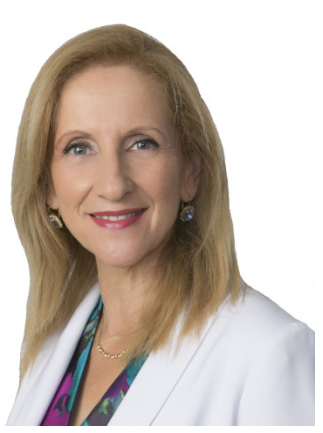

\section{Biography}

Gila Cohen Zilka, PhD, is Director of the Department for Teaching Social Studies and Communication at Bar-Ilan University; Head of the program for training mentors to work with children at risk, Achva Academic College.

Zilka's research mainly focuses on ICT, children in the digital environment and communication in the diversified media. The digital environment offers our children a vast amount of information, many behavioral models, and a new type of social communication. On the one hand, a digital environment opens them to new horizons for personal and social development. On the other hand, these new opportunities are accompanied by new risks. Zilka published two books on this subject; the books offer ways to empower children, parents, and educators in our age. For parents - Empowering Parents in the Social Media Age - The Three Element Way, and for educators and mentors - Empowering Educators and Mentors in the Social Media Age - The Three Element Way. 